\title{
Bad Biocitizens?: Latinos and the US "Obesity Epidemic"
}

\section{Citation}

Greenhalgh, Susan, and Megan Carney. 2014. "Bad Biocitizens?: Latinos and the US 'Obesity Epidemic."' Human Organization 73 (3) (September): 267-276. doi:10.17730/ humo.73.3.w53hh1t413038240.

\section{Published Version}

10.17730/humo.73.3.w53hh1t413038240

\section{Permanent link}

http://nrs.harvard.edu/urn-3:HUL.InstRepos:31771242

\section{Terms of Use}

This article was downloaded from Harvard University's DASH repository, and is made available under the terms and conditions applicable to Open Access Policy Articles, as set forth at http:// nrs.harvard.edu/urn-3:HUL.InstRepos:dash.current.terms-of-use\#OAP

\section{Share Your Story}

The Harvard community has made this article openly available.

Please share how this access benefits you. Submit a story.

Accessibility 


\title{
"WE ALREADY OWN THE ISSUE": LATINOS AND THE AMERICAN "OBESITY EPIDEMIC"
}

\author{
Susan Greenhalgh \\ Megan A. Carney
}

Forthcoming, Human Organization, Sept. 2014

Keywords:

Obesity, Latino Threat, Biocitizen, Let's Move!, Structural Vulnerability, Anti-obesity programs, Champions for Change, California

\section{"WE ALREADY OWN THE ISSUE": LATINOS AND THE AMERICAN "OBESITY EPIDEMIC"}

\begin{abstract}
:
For 15 years now the U.S. has been facing an "obesity epidemic" that, according to the dominant narrative, is harming the nation by worsening the health burden, raising health costs, and undermining productivity. Much of the responsibility is laid at the foot of blacks and Latinos, who have higher levels of obesity. Latinos have provoked particular concern because of their rising numbers. Michelle Obama's Let's Move! Campaign is now targeting Latinos. Like the national anti-obesity campaign, it locates the problem in ignorance and calls on the Latino community to "own" the issue and take personal responsibility for embracing healthier beliefs and behaviors. In this article we argue that this dominant approach to Latino obesity is misguided and even damaging because it ignores both the politicaleconomic sources of minority obesity and the political-moral dynamics of biocitizenship in which the obesity issue is playing out. Drawing on two sets of ethnographic data on Latino immigrants and U.S.born Latinos in southern California, we show that Latinos already "own" the obesity issue; far from ignorant, as members of a biocitizen society they are fully aware of the importance of a healthy diet, exercise, and normal weight. What prevents them from becoming proper thin, fit biocitizens is structural barriers associated with migration and assimilation into the low-wage sector of the American economy. Failure to create the normative body has led them to internalize the identity of bad citizens, assume personal responsibility for their failure, naturalize the conditions for this failure, and feel that they deserve this fate. We argue that the blaming of minorities for the obesity epidemic constitutes a form of symbolic violence that furthers what Berlant calls the "slow death" of structurally vulnerable populations, even as it deepens their health risks by failing to address the fundamental sources of their higher weights.
\end{abstract}

ACKNOWLEDGEMENTS: The authors would like to thank UC MEXUS for providing a dissertation research grant to conduct Carney's fieldwork, the participants in both projects, and the Comparative Border Studies Institute at Arizona State University for supporting Carney during the write-up of this article. We are also indebted to the two anonymous reviewers for offering additional valuable insights during the development of this article.

\section{OBESITY: "THE LATINO THREAT"}


For over a decade now, America has been facing an obesity epidemic that, according to the narrative of government, public health, and media sources, is threatening the nation by worsening the burden of disease, raising healthcare costs, and lowering productivity. Although the rate of increase has slowed or flattened in some groups, obesity levels remain high. In 2010, 35.7 percent of adults, and 16.9 percent of children and adolescents were obese (Flegal et al., 2010 and Ogden et al., 2012). In 2007-08 fully 68 percent of adults and 31.7 percent of young people were overweight or obese (Ogden et al., 2010).

Public health messages about the obesity epidemic invariably mention ethnic differences, in particular, the finding that blacks and Latinos consistently have higher prevalence of obesity than whites. In its latest report, the Center for Disease Control notes that Hispanics are 1.2 times more likely to be obese than non-Hispanic whites (the CDC uses U.S. Census racial/ethic terms), and they have the second highest rates of obesity in the U.S. (Flegal et al., 2012 and Ogden et al., 2010). Although blacks have higher obesity rates, Latino obesity is deeply worrying to the public health community because of demographic forecasts that predict rapid growth of the U.S.-based Latino population. Indeed, by 2060, one-third of Americans will be of Hispanic origin, up from one-sixth in 2012 (US Census Bureau, 2012). Read through the lens of cultural hysteria about the "threats" to the nation posed by Latino immigration (Chavez, 2007, 2008), these projections signal not only a likely expansion of the Latino obesity problem, but also a new perceived Latino threat to the nation.

Clearly, if Latinos (and blacks) are differentially burdening the nation, their excessive weight must be addressed if the obesity epidemic is to be brought under control and the nation restored to health. Public health interventions will not succeed, however, unless the forces driving the higher obesity prevalence are correctly understood. In this article, we draw from findings from our respective research projects in southern California to compare differences and similarities in anxieties and concerns about weight between foreign-born and U.S.-born Latinos to ask, among other things, what accounts for 
Latinos' higher weights?

When these ethnic differences were first uncovered, the public health literature tended to attribute the higher rates of obesity among minorities to cultural differences in health knowledge and body ideals. Minorities were said to have limited knowledge about healthful eating and exercising. Moreover, Latinos were described as being ignorant about biomedical knowledge and having larger than normal body ideals that combined unfavorably with increased "acculturation" to mainstream U.S. lifestyles (for examples, see Buscemi et al., 2011, Cachelin et al., 2006, Chamorro and Flores-Ortiz, 2000, Fitzgerald, 2010, Gomel and Zamora, 2007, Gordon-Larsen et al., 2003, Matheson et al., 2006, Perez-Escamilla, 2009 and Sussner et al., 2008). Latinos were also subject to the general stereotypes that apply to all fat people in the U.S.: they were widely seen as lazy, irresponsible, and a drain on social services (Chavez, 2008, 2012).

More recently, however, researchers have begun to underscore the role of structural factors in producing higher weights among Latinos. The American Journal of Preventative Medicine published a special issue in March 2013 reporting findings from the Salud America! Campaign - a national initiative to curtail Latino childhood obesity - that attributed overweight and obesity among Latinos to nutrientpoor food environments, poor exercise environments, and unregulated marketing of unhealthy foods to children (Ramirez and Ayala, 2013).

If structural factors bear significant responsibility for the heavier weights of Latinos, then an effective response would entail programs that improve job opportunities, raise wages, enhance food environments, ensure safer neighborhoods for exercise, and so on. Yet today's anti-obesity programs targeted at Latinos and other minorities rarely (if ever) take this approach. Rather, interventions adhere to what Guthman (2011) identifies as "problem closure," the process by which solutions to obesity are defined by conventional constructions of the problem of obesity, which then forecloses alternative 
interpretations and approaches.

As with other longstanding public health approaches to health problems - approaches that have become more prevalent with the spread of neoliberal ideologies and policies - efforts to reduce and prevent obesity continue to put the onus on individuals and families, calling on them to learn to eat better and exercise more so as to achieve normal weight. Notably, First Lady Michelle Obama has been promoting her Let's Move! campaign to eliminate childhood obesity with Latino audiences. At the 2013 annual conference of the National Council of La Raza (NCLR), the nation's largest Latino advocacy group, she placed responsibility for obesity on beliefs and behaviors in the Latino community and called on her listeners to "own this as a serious problem":

Right now, nearly 40 percent of Hispanic children in this country are overweight or obese. Nearly 50 percent are on track for diabetes... We all know that the food industry has some serious work to do when it comes to how they market food to our kids, but here's the thing, ultimately, we all have the power to decide whether or not to actually buy those foods. We need to step up. We need to own this as a serious problem in our communities. We need to admit that what we're doing simply isn't working anymore, and we need to start questioning the behaviors and beliefs that are making our kids sick. (Satchfield, 2013)

Explaining the First Lady's message, Jorge Plasencia, the Board Chairman of NCLR, said: "We have over 5,000 people [here] and each one of them can become delegates of sorts to promote healthy eating in their community... Now when you all go back home... make sure to go back and tell folks in your communities that they gotta eat healthy" (Satchfield, 2013). The implication here, conveyed through the messages of both First Lady Obama and NCLR's Board Chairman, is that Latinos have not questioned their own dietary practices. 
This emphasis on the individual responsibility of Latino families and communities is evident in a wide range of anti-obesity campaigns. For instance, the California-based Champions for Change program, coordinated by Network for a Healthy California, frequently disseminates dietary information in the form of healthy-recipe books at grocery stores, health fairs, and public schools. According to the program website, "Champions for change are people who are committed to helping their families eat more fruits and vegetables and be more physically active. They are also involved in making healthy changes in their neighborhoods" (www.cachampionsforchange.cdph.ca.gov, accessed 9/18/13). Promotional images of moms in the grocery store buying veggies and using a TV remote to turn off the television underscore the point that parents, especially moms, are responsible for their families' healthy practices. Since 2007, Champions for Change has been California's major anti-obesity program; in 2008 it conducted outreach with 1.6 million low-income, Latino adults (http://www.cdph.ca.gov/programs/cpns/Documents/BRO210_SEPT_2011.pdf, accessed 9/20/13). All of these messages imply that Latinos are less knowledgeable than other groups and that this lack of knowledge is what accounts for their higher weights.

Will the approach championed by the First Lady work? Do Latino families need more education about the health risks of consuming a high-calorie, low-nutrient diet with minimal to no exercise? Does the root of the problem lie in a lack of knowledge about healthy eating and failure of Latinos to "step up" and question their own behaviors and beliefs? What wider effects does the assumption of ignorance which gets embedded in programmatic interventions as well as the ubiquitous media messages about minority responsibility for the obesity epidemic - produce? What political work might it do?

Elsewhere, Greenhalgh (2012) has argued that the political dynamics of the American obesity epidemic constitute a morally-laden project in which an individual's deservingness of citizenship is perpetually held in question. The almost 15 -year-old "war on fat" works by creating a "biocitizenship 
society" in which, to be deemed a worthy, responsible American, each of us must become a virtuous biocitizen. A good biocitizen is one who devotes large amounts of time to dieting and exercising in order to maintain a medically "normal" weight, and who takes responsibility for ensuring that others in his social environment also become good biocitizens (Halse 2009; also Rose 2007). Although both men and women are expected to become thin, fit biocitizens, because of cultural norms making appearance more central to women's identities, and gendered norms making mothers responsible for health within the family, the burdens of biocitizenship - both achieving the slender, toned body oneself and ensuring others do likewise - fall more heavily on women. The main mechanism for the spread of biocitizenship culture is fat-talk, both biopedagogical (serving to inform) and bioabusive (serving to induce change through shaming). As a moral discourse, biocitizenship grants membership based on success in endeavors of personal health while excluding those who fail from the community of good Americans. Latinos thus now face yet a new, even more insuperable barrier to becoming "real" or "valued Americans": they must become good biocitizens who eat a certain way, move a certain amount, and maintain a certain weight, all the while ensuring that other Latinos do the same. Extensive research shows that in the U.S. today, the benefits to thin bodies and successful biocitizenship are economic, social, political, and cultural. Properbodied Americans are rewarded with better jobs and higher incomes, more friends and romantic prospects, superior access to state employment and benefits, and more positive representation in the media and other cultural venues (Puhl and Heuer 2009, Fikkan and Rothblulm 2011). Weight-centered biocitizenship thus affects belonging in the widest sense. The findings from our research suggest that virtually all institutions and actors in our society - from families and communities to doctors, schools, political officials, and corporations - actively manage and promote the terms of biocitizenship. Biocitizenship is so pervasive a feature of our culture and society that it seems that everyone everywhere is lecturing everyone else about being a good biocitizen.

The epidemiological knowledge that dominates public health research is not well positioned to 
answer the sorts of questions posed here. While large-scale epidemiological studies provide the big picture of obesity prevalence among different groups, they cannot uncover the nuances of how Latinos are dealing with the obesity issue and responding to being targeted for blame and reform. In-depth ethnographic knowledge can reveal these dynamics. By working to elicit people's own views of their lives, and by situating these views within the larger social context that informs them, ethnography can help to illuminate social, political, and economic conditions underpinning health disparities, and may offer insight as to what solutions may prove most effective in the long-term. In this article, we argue for a research agenda informed by ethnography that disentangles the social, structural, and intergenerational dynamics of higher prevalence of overweight and obesity among U.S-based Latino populations. By combining our two data sets, we are able to see the impact of the war on fat on a wider array of groups who might be expected to be affected differently: immigrants and U.S.-born Latinos, and parents and teens or young adults. Our data will show that regardless of immigrant status or age/parental status, all Latinos we worked with were deeply affected by the biopolitics of fat in the U.S.

As noted above, the data presented in this article are derived from our recent ethnographic studies with foreign-born Latino immigrants and U.S.-born Latinos in southern California. Greenhalgh gathered 245 3- to 8-page ethnographic essays from her students at the University of California, Irvine on "diet, weight, and the BMI in the everyday life of someone you know well." These essays were assigned for extra credit in her course "The Woman and the Body" in 2010 and 2011. Students received extra credit simply for turning in an essay; they were not graded on the content. Students could write about any topic they chose dealing broadly with weight. Roughly three-quarters were auto-ethnographies featuring the weight struggles of the young people themselves; the others described the struggles of family members or friends. The essays were assigned for pedagogical purposes, but after reading them and realizing their extraordinary potential, Greenhalgh sought permission from each student to use his or her essay in her research. When seeking their consent, she asked the authors to place the essay's subject in one of three 
economic categories, financially struggling, middle-class, or well-to-do family. Each was carefully defined in terms of income, job, and job stability of the main breadwinner, home ownership, and availability of disposable income. ${ }^{1}$

Of the 245 essays, 18 essays focused on Latino subjects. Greenhalgh also conducted 10 roughly hour-long interviews with Latino young people designed to understand body ideals and practices in the Latino community. These 28 cases form the basis of Greenhalgh's contribution to this article. Of the 28 subjects, 77 percent are women. Sixty percent are Mexican-American, 10 percent each Guatemalan- and Salvadoran-American, and 20 percent other or unknown. Most are U.S.-born citizens. They grew up all over southern California, with the largest percentages coming from Los Angeles, Orange, and San Diego Counties. Of the essay subjects, 38 percent grew up in financially struggling families, 44 percent in middle-income families, and 19 percent in well-to-do families (the others fell between these major categories). This is a high proportion of financially challenged families; for the 245 essays together, only 13 percent of the subjects were from economically distressed families. Greenhalgh also conducted largescale surveys of body ideals and practices as well as general ethnographic research in the southern California region. The results of these efforts inform her understanding of the essays that form the centerpiece of her discussion here.

Carney conducted 18 months of fieldwork in Santa Barbara County between 2008 and 2011 with low-income Mexican and Central American migrant women ( $\mathrm{N}=25)$ who were utilizing food assistance programs. These women served as key informants on the lived experience of food insecurity. Many studies, particularly from the field of public health, have framed obesity as a diet-related health condition with possible links to food insecurity (e.g., Buscemi et al. 2011; Gundersen et al. 2008; Kaiser et al. 2004; Pearce et al. 2009; Townsend et al. 2001); the food assistance programs observed by Carney prominently featured concerns about obesity. Carney recruited key informants through health and human service 
organizations in Santa Barbara County, and she collected data through semi-structured and life history interviews, dietary surveys, participant observation, and focus groups. Dietary surveys included a health survey component in which Carney asked key informants about self-perceived health status, and if and how weight factored into women's perceptions of health. She also conducted participant observation with members of the Santa Barbara County public health community who were involved in designing and implementing an obesity prevention campaign that identified Latinos as the target population. All interview and focus group interactions with key informants were conducted in Spanish and audiorecorded. Bilingual research assistants helped to transcribe recordings. Key informants in Carney's research received a modest monetary stipend for their participation.

This article highlights three main findings from our research. First, as poignantly illustrated through the voices of Latino youth in Greenhalgh's research, virtually all the Latinos we worked with already "owned" the obesity issue; far from being ignorant, they had been subject to biocitizenship influences for years and knew only too well what constituted a healthy diet and what levels of exercise promoted good health and normal weights. Second, they tried hard to integrate these practices into their lives, but the economic and social barriers proved too overwhelming, circumstances particularly notable in the cases of Latino immigrants from Carney's research. Structural constraints made it impossible for them to become good biocitizens. Third and finally, for both Latino immigrants and U.S.-born Latinos from our research projects, failure to become thin, fit biocitizens led them to internalize the identity of "bad citizen." Most assumed personal responsibility for this failure, naturalized the conditions preceding this failure, and came to feel that they deserved this fate. We turn to the concept of structural vulnerability (Quesada et al., 2011) in the paper's conclusion to argue that the impossible demands of biocitizenship get folded into a process of embodiment by which Latinos are further excluded from the category of good Americans who are regarded as deserving of the privileges of social belonging. 


\section{"WE KNOW ABOUT HEALTHY EATING, EXERCISE, AND WEIGHT"}

In Greenhalgh's research, Latinos were indistinguishable from the young people of other ethnic groups: regardless of cultural background, virtually everyone was knowledgeable about the necessity of eating well and exercising regularly to reach a healthy weight. This relatively high level of knowledge is illustrated by Angela, a Mexican-American woman who wanted to lose weight: "[She] eats very healthy and watches the amount of food she eats, and won't even have a bite of a cookie or a scoop of ice cream. She counts every single calorie, only eats 1000-1500 calories a day, reads nutritional facts, and goes to the gym at least three times a week."

Young Latinos were so knowledgeable about weight and health because their social worlds were full of dutiful biocitizens who readily informed them of their weight problem if they carried extra pounds and what they must do to fix it. Every essay in Greenhalgh's research mentioned the role of parents and/or relatives in conveying to their children the essentials of good biocitizenship that they had gathered from their own participation in U.S. society - by watching TV, viewing advertisements, visiting their kids' schools, going to grocery stories, and eating at fast food restaurants. Messages about diet, weight, and exercise pervaded these everyday experiences. Parents hearing these messages were concerned not only about their children's health, but also about their ability to fit in, be happy, and eventually find a partner in life. These concerns often started early in a child's life. Allison's case is typical: "My entire life I have always been chubby at the least... In third grade my mom put me on my first diet. My mom was always sure to let me know when I was eating the wrong things, or if she thought I should go exercise instead of sitting and watching TV... In the sixth grade, my mom took me to Weight Watchers for the first time." Diet, exercise, and weight are such fundamental features of American culture today that even recent immigrants were keenly aware of the importance of thinness to belonging. Sofia's parents, recent immigrants from Guatemala, insisted that their two daughters be thin because they wanted the girls to assimilate into mainstream Orange County culture and be accepted. So keen were they to guarantee their 
daughters' thinness that they gave them water pills to spur weight loss.

If parents taught kids healthful practices, knowledge of the BMI scale and the consequences of a bad BMI came primarily from interactions with health professionals. In roughly half the cases in Greenhalgh's research, young people learned their BMIs from doctors during a routine health examination or from nurses conducting school fitness tests, which in California are required of all fifth, seventh, and ninth graders. This was often the first time young people learned that their bodies were "abnormal"; for many it was a traumatic experience that precipitated a dramatic change in which they suddenly began to perceive themselves as bad and defective and in need of remediation. Ignacio described the experience this way:

I remember going to the doctor's office as she told my mother and me that I was considered overweight and a few pounds from being obese. I found this concept absurd... nonetheless it put the idea of obesity in my head. The doctor pulled out a BMI chart and told me what my ideal weight should be. As soon as my mother heard this, she became concerned for my health... It was at this point that I made a conscious decision to try to control my eating habits.

Lauren's encounter with her physician trampled her self-esteem:

When I was 10 years old, I went to the doctor's office for a routine check-up... I knew I had a weight problem, but no one had ever called me fat directly. This doctor told my mom that if she did not do anything soon I would be in danger of contracting diseases like high blood pressure, diabetes, and hypertension... I did not realize it at that time, but [that diagnosis] caused traumas in my life. My self-confidence was shot down. 
For AnneMarie it was a school-based fitness test that turned a happy, carefree child into a weightobsessed "fat girl":

In seventh grade I was expected to pass some sort of fitness test in my PE class. I happily stepped up onto the scale and then stepped aside as the nurse quickly calculated my BMI, something I had never heard of. She gave me my number, which was written in red, and explained to me that I was overweight and that I had to lose weight because my BMI was much too high... When she sternly looked at me and told me that I absolutely had to get my weight down, I was stunned... This was the origin of my horror of being fat.

Pedro learned the essentials of good biocitizenship not only from his doctor but also from school health classes:

When I was little I was overweight. I was like really big. I was like 160 in fourth grade. When my mom used to take my sister and me to the doctor, he would say, "You're fat, you know." Almost literally, he said in Spanish, gordo... Our weight was a big part of what we always talked about... In middle school and high school health ed classes, there was always someone to tell you what a nutritious diet is. But you hear it and hear it; I heard it often enough that I was like, "Eh, I know what it is."

If parents and medical professionals provided these young people with concrete knowledge about diet, exercise, and the BMI, interactions with their peers and popular culture made it more real, more personal, and often more uncomfortable, goading them into action. Essays evoked memories of being ridiculed by peers, underperforming in school sports, and feeling inadequate in comparison to popular media images of the ideal body. Ignacio recalled being routinely bullied by kids on the playground at the 
age of 12: "Other students would find it funny to pick on the fat kid. I would often be last to be picked for pick-up basketball games because I was fat and couldn't run as fast as the other skinnier guys." Lucia learned at an early age that her body size would keep her from being socially accepted:

I didn't need to be told by my doctor that there was something wrong with me; all I had to do was just look around and realize that society looked down upon overweight individuals such as myself... The last years of elementary school were when I experienced the most fat discrimination... I remember not being chosen for team activities, the cool kids never giving me more than a glance, and how I did not fit into the cultural obsession of slenderness evident in the fashion industry, on television, and in other types of media.

The ubiquitous media images of thin, fit bodies and the biobullying and social exclusion of peers are equally effective in conveying the message that heavier bodies merit scrutiny and criticism and must be rectified through dieting and exercise. If these cases are typical - and we surmise that they are in important ways - the notion that Latinos are unaware of the importance of diet, exercise, and maintaining medically normal weight has scant basis in social fact.

\section{TRYING BUT ALWAYS FAILING: THE INSUPERABILITY OF STRUCTURAL BARRIERS}

While findings from Greenhalgh's research highlighted the experiences of Latino youth, most of them the children of immigrants, findings from Carney's research underscored experiences of Latino immigrants, and women in particular. Low-income, immigrant women experienced undesirable changes to diet upon arriving to the U.S., followed by weight gain and negative health outcomes that were difficult to address amidst stressful work, family, and politico-legal circumstances. These women ranged in age from 24 to 60 (mean age of 38), and originated from Mexico (especially Guerrero, Michoacán, and Oaxaca), Honduras, and Guatemala. Few had obtained documented status while living in the U.S.; most were "sin 
papeles" (i.e., undocumented). Women's length of residency in the U.S. ranged from three months to as long as 30 years. Notably, all but one had children.

In Carney's research, the circumstances of migration intersected with other structural barriers that contributed to poor health and obstructed efforts to maintain a healthy body size. These findings are consistent with recent research by Florez et al. (2012) and Agne et al. (2012) that suggests that weight gain is endemic to the Mexican migration experience. Women in Carney's research ascribed certain aspects of post-migration life to this weight gain. These included: the convenience and affordability of unhealthy foods; isolation from social networks to support the retention of healthful behaviors; and stress from low-wages, multiple responsibilities in the home, and lack of time between jobs. Juliana (late thirties, from Guerrero), for instance, noted how demanding work schedules prevented immigrant mothers from preparing and sharing in nutritious foods: "Women don't have time, for the reason that they work. So they go buying something quick, perhaps for the reason of work. Because many times they eat this way, in large part, this is what does them harm, makes them gain weight.” Malena (late thirties, from Guerrero) assigned herself to this category of working mothers; as the sole provider for her children, she would regularly arrive home late from her job as a hotel maid with no time or wherewithal to prepare a meal: "[We get] McDonald's or pizza [instead], because it is cheap."

Similar to the descriptions of these women, the child of an immigrant family in Greenhalgh's research recalled how the move from Guatemala to the U.S. made everyone in her family gain weight: "In Guatemala... portions are much smaller than they are here in America. It is customary to eat at home every night for dinner, and it is rare that a family eats out. It is also much more uncommon to eat fast food. However, making the move here changed my and my family's customs drastically. Since we began eating out more and consuming more fast food, everyone's weight shifted [i.e., rose]." 
Luisa (early forties, from Michoacán), recalled drastic changes to her diet upon arriving to the U.S.: "When I got here, when one arrives here from Mexico, you see so much variety and you say 'in Mexico we never ate like this.' The truth is that [at first] I ate a lot. Because I was hungry for everything. I was longing for sweets, everything that we did not have in Mexico." This type of binge eating, as noted by Luisa, pervaded women's accounts of adjusting to the harsher conditions of life that they encountered in the U.S., which included a sense of social isolation. As Dolores (late thirties, from Guerrero), explained: "One suffers when they come here because they do not know anyone. Everything is different. When one arrives, one feels sad and alone, not knowing what to do."

The experience of social marginalization associated with the process of immigration also had effects for the Latino youth in Greenhalgh's research. In these cases, exposure to social trauma and life disruptions led them to turn to compulsive over-eating as a coping strategy, resulting in weight gain. Perhaps because of the higher level of poverty, Latino kids were more likely than kids of other ethnic groups to suffer individual and family traumas that were beyond their control. In one case, it was the trauma of immigration, followed by a parental breakup and the subsequent reappearance of a father who had been jailed, that led a young woman to quit her diet and exercise routine and to start eating more to calm her nerves. In a second case, a family medical emergency and the fear of losing a mother forced a young boy to become his father's right-hand man; with no control over his life circumstances, he overate and gained weight. In a third case, a young woman ate more compulsively to dull the pain of fat abuse. Ridiculed by a boy on the school playground who yelled, "Why do you want the ball, you are so fat, I'm sure you can't even shoot!” Lauren was crushed: “That day is one I will never forget, he broke me down. For years after that I felt ugly, fat, disgusting, not good enough... So I began to eat. Food was delicious and it made me feel good... Slowly but surely I gained more and more weight until the point where I was borderline obese." 
Although women in Carney's research desired to establish healthier diets within their families, the ubiquity of certain "junk" (comida chatarra) and "fast foods" (comida rapida, i.e., burgers, pizza, processed bread, and fast food) frequently undermined these women's efforts. Natalia (early fifties, from Oaxaca), a mother of four, expressed dismay with the meals served at her son's school: "I don't like junk food. I fight with [my son] because I prefer that he'd eat a plate of lentils rather than a burger. Because, for example, burgers are eaten in school or the children are given pizza. So I prefer that in my house, [he eats] rice with chicken. Lentils. A bit of fish with salad." In addition to school lunches, which often contained items - such as pizza and hamburgers - perceived as chatarra by the mothers, children also acquired snacks in the form of chatarra from local street vendors who carted around items for sale in women's neighborhoods. Some women even blamed their husbands - the occasional purveyors of fast food - as undermining their efforts to ensure comida saludable. Juliana, for example, relayed an incident on Mother's Day when her husband arrived home with pizza after she had prepared a healthy meal. Referring to his actions, she said, "Sometimes these barriers exist in your own home."

In reporting on the undesirable changes to their bodies that they observed since arriving to the U.S., immigrant mothers in Carney's research complained of feeling helpless and depressed. Marisol, a single mother in her early thirties, struggled to manage her weight while being the sole financial provider for her three daughters. She related high levels of stress from working multiple part-time jobs: "I have gained a lot of weight and I feel that I can't change my body. I feel really tired, really stressed." Linda (late thirties, from Michoacán) reported problems with weight in her entire family. She expressed concern for the weights of her son and husband; meanwhile she framed her own weight gain in terms of stress from work, managing her household, and coping with her husband's alcoholism:

I think I'm a bit overweight because of my husband being fat. He keeps putting on [weight]. But he drinks, and I think this makes him fat. He likes to drink a lot, a lot, everyday. I've gained eight 
pounds and I think it is because I'm not eating well, because I'm not keeping to a schedule. My son is also overweight but he's been this way since he was really little. I think that now my weight is really affecting me, because I have back pain. I'm stressed because my back hurts me so much - three months ago I was at a normal weight. I was always 138 pounds and now I'm 142, no, 146. I feel bad. I need to lose weight. I think [maybe] stress makes one gain weight? Because I'm really stressed. I stress all the time and I think that is what this is. I get nervous but in the form of hunger. Anything I put into my mouth, bread, a cookie, makes me gain weight when I'm stressed. The stress also comes from driving without a license all the way to my job. It comes from needing to pick up my kids quickly, to get home to make the meals. Now my husband is getting home from work very late, like at eight o'clock at night, so every responsibility falls on me: go to work, leave kids at school, return, get them from school, make dinner, do the laundry, everything is for me to do. For these reasons I feel so much stress. But I can't stop working because when I do, I feel stressed again because there is no money to pay the rent, the bills, for things we need. If it is not one thing, it is another.

As Linda articulates that it is she, rather than her husband, who is charged with overseeing so many aspects of the household, her case suggests that the changes associated with adjusting to life in the U.S. and translating to negative health outcomes, including increased anxiety, affect women disproportionately (for further discussion of this gendered suffering, see Carney forthcoming).

In terms of gender differences, there was also some evidence from our research that Latinas felt more pressure than men to conform to gendered body ideals. For instance, one woman from Carney's research pursued somewhat extreme measures in attempting to control her weight. As the accumulated result of many years of compulsive eating since migrating to the U.S., Brenda (mid-fifties, from Mexico City) decided to address her weight problem by electing to undergo gastric band surgery. However, since 
her doctors in the U.S. would not approve her for the procedure, she drove across the border to a clinic in Tijuana. Although the surgery enabled her to lose weight, her desired results proved only temporary:

I have everything: high blood pressure, diabetes, high cholesterol. I weighed 212 pounds so I got a gastric band. The truth is I had to do it because I'm a compulsive eater; I'm one of those people for whom everything revolves around food. The truth is that I love food. I don't have diabetes for just any reason - I love sweets. At last, I try to not have sweets in our home because the sugar makes me feel bad. For 12 years I've suffered from diabetes. Recently, when I had my surgery I went from 200 pounds to 135 pounds. But the truth is that I started to feel that my [gastric] band was opening up. Here they told me that you had to be at least 100 pounds overweight [to qualify for the surgery] but I explained to them that I have diabetes, high blood pressure, but they still told me "no." So my husband and I made the sacrifice of going to Tijuana for the surgery. When I reached 135 pounds I started to eat and I realized that the food was passing through too quickly. In less than three months I had gained 25 pounds. I felt that the band had opened. The last time that I visited my doctor in Tijuana I was at 185 pounds. I need them to adjust the band. Yes, I've had to take radical measures because the truth is I'm not like most people. I cannot stop [eating]. I always start to eat [too much].

Arguably, Brenda's efforts to lose weight vis-à-vis elective surgery were not successful because they did nothing to address her tendency toward compulsive eating, a behavior she had developed since living estranged from most of her children (who were still in Mexico) and spending much of her time alone. While Brenda's experience perhaps edges on the extreme, many women in Carney's study cited how structural factors such as financial constraints and social isolation steered them toward gain weight or prevented them from losing it, despite attempts at dieting and exercise. 
For U.S.-born Latinos raised in low-income communities, these same forces made it difficult to keep their weight down. Pedro knew the diet-and-exercise mantra, but a lack of money undermined his efforts to put it into effect:

In the past year and a half I've gained 70 pounds. [au: to BMI 43.6] I had knee surgery - to repair a meniscus that I tore at the gym... I had the surgery like six months later because I didn't have the insurance. I was in bed and depressed because I couldn't work out... I've [had to] put the whole working-out thing on the backburner for now... The week my son was born, my girlfriend and I had Jack in the Box three times a day for a week. There was no time to cook... Everyone knows that fruits and veggies are good for you. But you don't always have fruits [available to eat]. We don't buy fruits a lot because they expire and we forget about them. Or it's hard to buy enough fruit for every day because it's not that cheap. We're getting food stamps - actually, free food from WIC - right now, and it's a limited amount... We just [had] a really big expense that we weren't expecting, so come November or December, we're like, eh, we don't know where our money will be coming from. We just stocked up on Costco foods; we filled our fridge really bad... We don't know if we'll have money later on. At least we will have food.

When financial constraints are so severe that urgent surgery must be postponed and having any food to eat is a worry, following the dietary and exercise rules of good biocitizenship is an impossible dream.

\section{FEELING "IRRESPONSIBLE" AND "UNWORTHY": BAD BIOCITIZENS AND BAD MOMS}

We saw above that for heavyset Latino youth, feelings of being inadequate often started in childhood with the receipt of a non-normal BMI score. Such feelings persisted into young adulthood. The young people in Greenhalgh's research internalized the shame associated with being overweight in our society and took on the identity of the "bad biocitizen" who is "lazy," "irresponsible," and therefore undeserving of full 
inclusion in the political community. In high school, AnneMarie's bad BMI - in the high 20s, marking her as unhealthy and overweight - "warped the image of my existence in society," making her feel guilty and inadequate. After gaining back 15 pounds she had lost, Lucia:

began to feel guilty about the unhealthy foods I ate. I began thinking about my weight every day... Feeling "fat" when I didn't exercise three times a week is something I considered lazy and due to my lack of focus. Not going out shopping... on "fat" weeks is something that I started then... if I had been naughty and overate with larger portions... This constant thinking of weight also affects the way I perceived my acceptance into society.

Pedro defended himself from the common view that people like himself who fail at good biocitizenship are "lazy." Deep down, however, he felt that there was something very wrong with him and that his fatness and his failed efforts marked him as undeserving of the respect shown to those who succeed:

[Two years ago] I was not eating too well so in a few months I went down [from 230] to 200. I felt really good and tried to maintain that weight. I have pictures here [in my phone] because I need to know what I can look like - my potential. Because if [I don't have the photos], I'm just like, I feel bad a lot of the time... I hate it, you know, because I've seen what I can do... I've tried - I try eating healthy, I try eating small portions, you know... I made an effort, it's not that I'm lazy. That's a misconception a lot of people have - that overweight people are just lazy. But they're not. I've tried, you know. I've been 70 pounds lighter, and I've lost weight. And I have other things to do. But then you have other people who have the same stuff to do, but they weigh less. You think, you know, that something's wrong with you. You think you're not - I don't know - I think I'm doing something wrong. I think when I diet alone, I can control my weight at 
least to a more reasonable level. Like maybe 220 or 230 , instead of [my current] 270 or 260 . [au: BMI 42-43.6] But it's hard, I just don't know how to do it.

In addition to feeling like "bad citizens," women from Carney's research feared the possibility of being perceived as "bad mothers." Many of the messages stemming from the field of public health reinforce the notion that Latina moms are not taking proper care of their progeny. Campaigns for preventing childhood obesity such as Salud America!, for instance, gesture to changes in dietary behaviors that assume a mother's oversight. Thus, particularly blameworthy in the anti-obesity rhetoric is the Latina mother, who is yet again being portrayed as incompetent in overseeing her own health as well as that of her children (Horton and Barker, 2009, Inda, 2007 and Molina, 2006).

Aside from desiring to evade social scrutiny around their own bodies, immigrant women in Carney's research strived to distinguish themselves from so-called "bad mothers" by denigrating other women they knew who apparently worked too much and were not available to prepare healthy meals for their children. Olivia (late twenties, from Guerrero), for instance, described working mothers as too relaxed about their children's diets: “The problem that children eat junk food is the problem of [a mother]...We have to find options to buy better food or to make food at home. Because here, in this country, as mothers work, it is easier to buy prepared food or to take your kids to McDonald's. But it depends on how you, as a mother, provide them with healthy food." Statements such as Olivia's reproduced negative depictions of single mothers and operated as a form of symbolic violence against those who were already struggling with both limited financial resources and social capital.

These cases of Latinos whose subjectivities seem bombarded by the impossible demands of society to perform as good biocitizens suggest that current approaches to addressing the obesity epidemic among minorities may reproduce conditions of structural violence and translate into further social 
suffering. Our data on Latinos support Greenhalgh's (2012) observation that rather than "producing thin, fit, happy young people, the war on fat is producing a generation of tormented selves" (p. 484). We see similar repercussions unfolding for Latinos, repercussions that compound their structural vulnerability in U.S. society.

\section{THE OBESITY EPIDEMIC AS A NEW SOURCE OF STRUCTURAL VULNERABILITY: CONCLUDING THOUGHTS}

Our research reveals that both Latino immigrants and U.S.-born Latinos feel increasingly anxious and troubled about their bodies, anticipating the onset of an acute sense of exclusion from society. The impossible demands of biocitizenship operating alongside public sentiment that blames Latinos for harming the nation, together conspire in yielding this sense of exclusion and in delineating the parameters of inclusion. Thus, Latinos are effectively blocked from exhibiting good biocitizenship, and subsequently from enjoying the privileges of social belonging. Among the younger generation of U.S.-raised Latinos, both men and women, subject to pervasive pressures in their social worlds, were anxious about achieving the proper, thin, trim body. In the older immigrant generation of parents, women bore a much greater responsibility for following biocitizenship norms. Even as they tried to keep their own weight down, they were charged with ensuring that their children were raised in healthful environments, a project their husbands, apparently less concerned about weight, sometimes undermined.

Consistent with a rhetoric stressing the economic burden that obesity imposes on U.S. society, it seems clear that the public concern about the girths of Latinos serves larger political-economic interests. As Latinos strive - and generally fail - to embody the principles of good biocitizenship, barriers to this effort become increasingly internalized and normalized, so that the emotional angst around one's body size, or other feelings of inadequacy (Gonzales and Chavez 2012; Horton and Barker 2010), are viewed as natural and deserved. Relegating Latinos and other minorities to a position of marginality in this way 
allows for their continued exploitation as workers in the lower rungs of the U.S. labor economy (Guthman, 2011, Holmes, 2013).

In this article we have sought to disrupt the spotlighting of Latinos in America's "obesity epidemic." This spotlighting itself constitutes a form of structural violence, one that furthers the "slow death" of structurally vulnerable populations. In discussing preoccupations with obesity in the U.S., Lauren Berlant (2007) defines slow death as: "the physical wearing out of a population and the deterioration of people in that population that is very nearly a defining condition of their experience and historical existence" (p. 754), or in other words, the slow attrition of recognizing oneself as deserving of a dignified existence. Rather than enabling Latinos and other minority groups to overcome the oppressive social, economic, and political conditions that systematically ostracize them as "lesser" bodies that produce less value for society, anti-obesity programs frame their agency as "destructive" (Berlant, 2007:765), leading them to feel further ashamed, responsible, and bad about themselves. An ontology predicated on the thin body as a deserving body is highly problematic because it relegates many to this degraded category. Thus, the always-already failing biocitizen is one who also comes to accept the view of him or herself as less deserving of dignity and belonging.

Although the relatively high levels of Latino obesity pose health risks that are worrying and need to be addressed, current public health interventions into "overweight" individual bodies caused by "Latino ignorance" have little chance of working. Their failure to address some of the most fundamental sources of higher weights in the Latino community can be seen as compounding the health problems, as the education-focused programs, in place now for many years, fail to miss their mark. Their limited success adds to the urgency of finding more effective solutions. Even as we search for more effective ways to address the health problems, we need also to redress the general malaise that has emerged from a practice of shaming and blaming minorities for dragging the nation down with their higher weights. 


\section{REFERENCES}

Agne, A. A., et al.

2012 The Cultural Context of Obesity: Exploring Perceptions of Obesity and Weight Loss Among Latina Immigrants. Journal of Immigrant and Minority Health 14(6):1063-1070.

Berlant, L.

2007 Slow Death (Sovereignty, Obesity, Lateral Agency). Critical Inquiry 33(4):754-780.

Buscemi, J., B. M. Beech \& Relyea, G.

2011 Predictors of Obesity in Latino Children: Acculturation as a Moderator of the Relationship Between Food Insecurity and Body Mass Index Percentile. Journal of Immigrant and Minority Health 13(1):149-154.

Cachelin, F., Monreal, T. \& Juarez, L.

2006 Body Image and Size Perceptions of Mexican American Women. Body Image 3(1):6775.

Carney, M. A.

Forthcoming The Biopolitics of 'Food Insecurity': Towards a Critical Political Ecology of the Body in Studies of Women's Transnational Migration. Journal of Political Ecology.

Forthcoming "La Lucha Diaria": Migrant Women in the Fight for Healthy Food. In Off the Edge of the Table: Women Redefining the Limits of the Food System and the Experience of Food Insecurity, Janet Page-Reeves (ed.). Lanham, MD: Lexington Press.

Chamorro, R. \& Flores-Ortiz, Y.

2000 Acculturation and disordered eating patterns among Mexican American women. The International Journal of Eating Disorders 28(1):125-129. 
Chavez, L. R.

2012 Undocumented immigrants and their use of medical services in Orange County, California. Social Science \& Medicine 74(6):887-893.

2007 A Glass Half Empty: Latina Reproduction and Public Discourse. In Women and Migration in the U.S.-Mexico Borderlands: A Reader. P. Zavella and D. Segura, eds. Durham: Duke University Press.

2008 The Latino Threat: Constructing Immigrants, Citizens, and the Nation. Stanford: Stanford University Press.

Fikkan, J. L. and Rothblum, E. D.

2012 Is Fat a Feminist Issue: Exploring the Gendered Nature of Weight Bia. Sex Roles: A Journal of Research 66(9):575-592.

Fitzgerald, N. 2010 Acculturation, Socioeconomic Status, and Health Among Hispanics. NAPA Bulletin $34: 28-46$.

Flegal, K. M. et al.

2010 Prevalence and trends in obesity among US adults, 1999-2008. JAMA-Journal of the American Medical Association 303(3): 235-241.

2012 Prevalence of obesity and trends in the distribution of body mass index among US adults, 1999-2010. Jama-Journal of the American Medical Association 307(5):491-7.

Florez, K. R., et al.

2012 Mexico-United States Migration and the Prevalence of Obesity: A Transnational Perspective. Archives of Internal Medicine 172(22):1760-1762. 
Greenhalgh, S.

2012 Weighty subjects: The biopolitics of the U.S. war on fat. American Ethnologist $39(3): 471-487$.

Gomel, J. N. and Zamora, U. A.

2007 English- and Spanish-speaking Latina mothers' beliefs about food, health, and mothering. Journal of Immigrant and Minority Health 9(4):359-367.

Gonzales, R.G., and L.R. Chavez

2012 "Awakening to a Nightmare": Abjectivity and Illegality in the Lives of Undocumented 1.5-Generation Latino Immigrants in the United States. Current Anthropology 53(3):255-281.

Gordon-Larsen, P., et al.

2003 Acculturation and overweight-related behaviors among Hispanic immigrants to the US: the national longitudinal study of adolescent health. Social Science \& Medicine 57(11):20232034.

Gundersen, C., et al.

2008 Food security, maternal stressors, and overweight among low-income US children:

Results from the National Health and Nutrition Examination Survey (1999-2002). Pediatrics 122(3):E529-E540.

Guthman, J.

2011 Weighing In: Obesity, Food Justice, and the Limits of Capitalism. Berkeley: University of California Press.

Halse, C.

2009 Bio-Citizenship: Virtue Discourses and the Birth of the Bio-Citizen. In Biopolitics and the 'Obesity Epidemic.' J. Wright and V. Harwood, eds., pp. 45-59. New York: Routledge.

Holmes, S. M. 
2013 Fresh Fruit, Broken Bodies: Migrant Farmworkers in the United States. Berkeley \& Los Angeles: University of California Press.

2011 Structural Vulnerability and Hierarchies of Ethnicity and Citizenship on the Farm. Medical Anthropology 30(4):425-449.

Horton, S. \& Barker, J. C.

2010 Stigmatized Biologies: Examining the Cumulative Effects of Oral Health Disparities for Mexican American Farmworker Children. Medical Anthropology Quarterly 24(2):199-219.

2009 "Stains" on their self-discipline: Public health, hygiene, and the disciplining of undocumented immigrant parents in the nation's internal borderlands. American Ethnologist 36(4):784-798.

Inda, J. X.

2007 The Value of Immigrant Life. In Women and Migration in the U.S.-Mexico Borderlands. P. Zavella and D. Segura, eds. Pp. 134-157. Durham: Duke University Press.

Kaiser, L. L., et al.

2004 Choice of instrument influences relations between food insecurity and obesity in Latino women. American Journal of Clinical Nutrition 80(5):1372-1378.

Matheson, D. M., et al.

2006 Do Mexican-American mothers' food-related parenting practices influence their children's weight and dietary intake? Journal of the American Dietetic Association 106(11):18611865.

Molina, N.

2006 Fit to Be Citizens?: Public Health and Race in Los Angeles, 1879-1939. Berkeley: University of California Press. 
Ogden, C. L., et al.

2010 Prevalence of high body mass index in U.S. children and adolescents, 2007-2008. JamaJournal of the American Medical Association 303(3):242-9.

2012 Prevalence of obesity in the United States, 2009-2010. NCHS Data Brief No. 82, January, pp. 1-7.

Pearce, J, et al.

2009 A National Study of the Association Between Neighbhourhood Access to Fast-Food Outlets and the Diet and Weight of Local Residents. Health Place 15(1):193-7.

Perez-Escamilla, R.

2009 Dietary Quality among Latinos: Is Acculturation Making Us Sick? Journal of the American Dietetic Association 109(6):988-991.

Puhl, R. M. and Heuer, C.A.

2009 The Stigma of Obesity: A Review and Update. Obesity 10:1-24.

Quesada, J., Hart, L. K. \& Bourgois, P.

2011 Structural Vulnerability and Health: Latino Migrant Laborers in the United States. Medical Anthropology 30(4):339-362.

Ramirez, A. G. \& Ayala, G. X.

2013 An Introduction to Salud America!: A Research Network to Prevent Obesity Among Latino Children. American Journal of Preventative Medicine 44(3S3):175-177.

Rose, N.

2007 The Politics of Life Itself: Biomedicine, Power, and Subjectivity in the Twenty-first Century. Princeton: Princeton University Press.

Satchfield, S. 
2013 Michelle Obama speaks out about childhood obesity during N.O. visit.

www.fox8live.com, July 30, accessed 8/26/13.

Sussner, K., et al.

2008 The Influence of Immigrant Status and Acculturation on the Development of Overweight

in Latino Families: A Qualitative Study. Journal of Immigrant and Minority Health 10:497-505.

Townsend, M. S., et al.

2001 Food insecurity is positively related to overweight in women. Amer Inst Nutrition

131(6):1738-1745.

US Census Bureau

2012 U.S. Census Bureau Projections Show a Slower Growing, Older, More Diverse Nation a Half Century from Now. Washington, D.C.

${ }^{1}$ The economic categories in Greenhalgh's research were defined as follows:

\section{Financially struggling family}

Main breadwinner probably has blue-collar type of job

Main breadwinner may not have stable or steady work

Probably live in a rental apartment

Not always enough money to buy the things they want

\section{Middle-class family}

Main breadwinner has steady work and makes a pretty good income

Main breadwinner may own a small business, be a middle manager, or have a professional job

Probably own their home

There is money for some extras, but the family has a habit of economizing

Well-to-do or financially privileged family

Main breadwinner has stable job and earns lots of money

Main breadwinner may work in the professions, law, or business

Owns their home, lives in an especially nice or expensive home

There is ample money to buy nice things 